\title{
Self-Care practices for anxiety during the COVID-19 pandemic in the UK in adults
}

\author{
Mr. Antony Laban-Sharman, Dr. Anne Majumdar
}

Faculty of Sport, Allied Health \& Performance Sciences, St. Mary's University, London, United Kingdom

\begin{abstract}
Introduction. The National Health Service cannot chronically sustain the overwhelming demands being placed on it due to financial cuts, staff numbers and presence of Covid-19. As a result, anxiety levels are on the rise thus increasing the need for effective self-care behaviors.
\end{abstract}

Purpose: The purpose of this study was to comprehend and acknowledge the profound influence Covid-19 has had on anxiety levels and explore what behaviors people engage in to manage their perceived stress levels themselves.

Methodology: This study was an exploratory mixed-methods design consisting of 110 selfreferred adults aged 18-65 with anxiety completed an online survey guided by the "Harvard Anxiety and Depression Scale". Data collected from the free-text questions were analyzed using the thematic analyses method to evoke the most relevant themes and generate an evidencebased narrative.

Results and Discussion: Self-care behaviors used for anxiety self-management pre and during lockdown were walks, virtual family/social peer support, cooking and aerobic exercise. Additionally, it was apparent that a lack of ongoing family/social support was a key predictor for the proclivity of anxiety-inducing thoughts to be experienced. Interestingly, individuals who continually engaged in activity experienced positive mood states irrespective of the current lockdown environment.

Conclusion: This study adds to novel literature on the current anxiety levels of adults living in the UK under the Covid-19 pandemic and what self-care behaviors people implement to selfmanage their anxiety levels. This study stresses the significance of ongoing peer support as a self-care behavior that can act as a positive meditator for healthy cognitive processes to ensue. Therefore, future self-care programs advocating this strategy may, if not prevent, slow down the rising cases of anxiety and ill mental health due to the uncertain environment of Covid-19

\section{Keywords}

Anxiety, Mental Health, Self-Care, Covid-19, Qualitative.

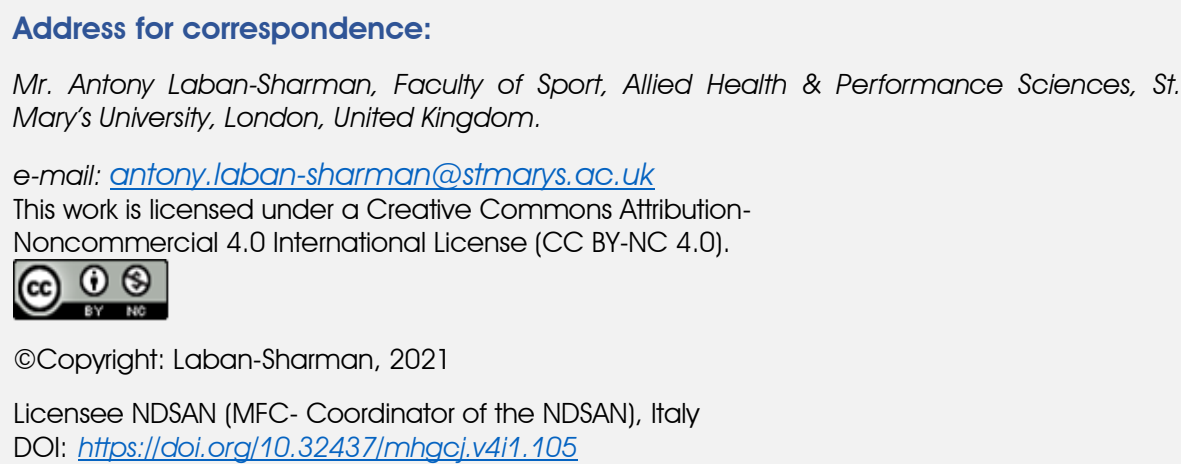

Submitted for publication: 18 April 2021

Received: 21 April 2021

Accepted for publication: 28 June 2021 


\section{Introduction}

Acknowledged in literature as a "feeling of unease, such as a worry or fear, that can be mild or severe depended on the perceived threat/outcome" (National Health Service [NHS], 2018a), anxiety is ongoing problem for the NHS in England. Currently, 1 in 6 adults, aged $18-65$, experience some form of anxiety with an additional 2.1 million individuals accessing the NHS Mental Health Service (MHS) in 2018/19 (Baker, 2020).

Additionally, the NHS at present spends $£ 13$ billion yearly on MHS which equates to a total of $14 \%$ economic distribution from local NHS resources (Baker, 2020).

Moreover, these issues are now further amplified by the presence of the Coronavirus Disease 2019 (COVID-19). Despite its recent existence, Covid-19 has had a significant influence on all the domains of society, including physical and mental health in the United Kingdom (UK) (Holmes et al., 2020). For instance, Kef (2021) and Sahu and Kumar (2020) suggest that social media platforms are spreading pseudo claims about the severity of Covid-19 and amplifying already high tended levels of anxiety.

More importantly, literature suggests that ill psychological consequences from the pandemic are expected to be profound due to numerous social determinants of health being influenced by the pandemic such as education attainment (Public Health England, 2018), inequitable income distribution (Department of Work \& Pensions [DWP], 2019) and unemployment issues (Foley, 2020). Moreover, the "stay home, protect the NHS, save lives" initiative (Freedman, 2020) may induce further consequences of ill mental health as even though the government initiative was created to reduce the prevalence of infectivity, the "by-products" of such an approach led towards increased levels of loneliness, social isolation, loss of work due to the economic crisis and the media generating distress around the virus that all contributes towards the probable development of depression, anxiety and even self-harm (Holmes et al., 2020; Mahase, 2020). Specifically, as revealed in Holmes et al. (2020) survey of the general population in the UK capturing the "mental health concerns due to the impact of Covid-19", social isolation, loneliness and personal economic difficulties seem to be the primary concerns for people that are also key predictors for anxiety, depression, stress and negative feelings (Elovainio et al., 2017; Frasquilho et al., 2015; Matthews et al., 2019).
Additionally, the fear of relationship loss, thoughts of uncertainty about the future, bereavement and lack of contact with family members were all common themes amplifying the overall feeling of anxiety (Holmes et al., 2020; Mahase, 2020).

Thus, it is paramount to implement costeffective practices that will inhibit the sustained feelings of loneliness/anxiety and support feelings of belonging and engagement to preserve the mental health of individuals living in the UK post pandemic (Connor \& Kirtley, 2018).

Additionally, access to ongoing support for MHS across the country have been significantly reduced due to the significant change in work environment and growing demand thus further increasing the levels of concern for health practitioners as it is reported that less than a third of individuals who commit suicide are usually in contact with a MHS within the last 12 months before death (Appleby, Shaw, \& Amos, 1997). Hence, increased ongoing access to MHS is paramount post pandemic however, alternative/complementary health-promoting "self-care" (SC) behaviors may be an appropriate cost-effective approach to not only reduce the demand on the MHS but to also support and evoke individuals to develop a sustainable "toolkit" of behaviors that will enable adults to manage their anxiety themselves.

\section{The need for "self-care" (SC) in the UK}

At present, SC is defined as "the ability of individuals, families and communities to promote health, prevent disease, maintain health, and to cope with illness and disability with or without the support of a healthcare provider" (World Health Organization [WHO], 2019). In a concise manner, SC represents an idea and philosophy for people to be more proactive about their own health (Bhuyan, 2004; Dean \& Kickbursch, 1995).

In other words, SC can act as an embodying philosophy to help people prevent and management the onset of anxiety and comorbidities that not only improves their quality of life but simultaneously, would reduce cost, pressure and stress on the NHS.

There are numerous behaviors categorized as SC however, the most common SC approaches/activities presented in literature to manage anxiety in adults are yoga (NHS, 2018b; Stussman, Black, Barnes, Clarke, \& Nahin, 2015), mindfulness (Aherne et al., 2016; Decker, Brown, Ashley, \& Lipscomb, 2019), exercise (ACSM, 2016; Mikkelsen, Stojanovska, Polenakovic, Bosevski, \& Apostolopoulos, 2017), cooking (Farmer, Leonard, \& Ross, 2018; Utter, J., Denny, 
Lucassen, \& Dyson, 2016) and peer support (Gillard, 2019; Puschner, 2018).

Thus far, it seems that peer support, through the phenomenon of "socialization", may be the most reliable and valid method of SC for anxiety management as positive outcomes can be seen in a variety of settings such as substance addiction and abuse ( $\mathrm{O}^{\prime}$ Connell, Flanagan, Delphin-Rittmon, \& Davidson, 2017), clinical populations with mental health disorders (Bocking et al., 2018), ongoing mental health peer support for students (Byrom, 2018), war veterans (Weir, Cunningham, Abraham, \& Allanson Oddy, 2019) and peer support within communities to reduce mental health hospital admissions (Lawn, Smith, \& Hunter, 2008).

Peer support is a practice where individuals vicariously share lived experiences of discomfort and suffering, form an interpersonal connection, and collectively learn and support one another ongoing (Gillard, 2019; Puschner, 2018). It isn't clear what precise mechanism is responsible for such outcomes however, the phenomenon of "socialization" and "empathy" (Smith, 2006) in accordance with the social cognitive theory (SCT) (Bandura, 2004) may offer some explanation; as individuals who engage in socialization, spark a dialogue where individuals can "vicariously share emotions and thoughts" fostering interpersonal closeness (Smith, 2006) leading towards a positive mood state in conjunction with a positive behavioral feedback loop (Bandura, 2004) increasing the probability for these individuals to re-engage in socialization and further reducing the chance for negative thoughts and feelings to be experienced. Relating this to Covid-19, it is highly probable that people who did not experience ongoing social or familial support would be at risk of experiencing negative cognitive processes fueled by anxiety.

Still, it is necessary to understand the influence Covid-19 has had on anxiety levels and explore what behaviors people engage in to manage their perceived stress levels themselves as it'll guide future interventions to focus on SC behaviors that individuals choose and perform consistently and competently. This is important as future interventions focused on SC behaviors that people enjoy reduces the threat of autonomy, in conjunction with perceived behavioral competence that has been associated with improved self-efficacy which is a strong predictor for behavior adoption and adherence (Bandura, 1997; Ryan \& Deci, 2000).

Furthermore, this approach should help with the sustained self-management of anxiety levels in the future

\section{Purpose}

To explore the perceived effect of Covid-19 on anxiety levels and what SC behaviors adults use to manage it. The research question is as follows:

- To explore the anxiety experienced by adults during the covid-19 pandemic and approaches used to manage it?

Further objectives:

- To explore the experiences of people during lockdown and their impact on wellbeing.

- To identify peoples' self-care approaches during the lock-down period.

- To inform healthcare practitioners on areas of focus and potential self-care approaches that could be encouraged in the future management of patients who face similar circumstances.

\section{Methodology}

\section{Study Design, Participant Characteristics \& Recruitment}

This study was an exploratory study with a mixed-methods design with the primary focus being on the qualitative findings. Following full ethical approval from the St Mary's University ethics committee, this study aimed towards a purposeful snowball sampling plan. Kotrlik and Higgins (2001) suggested that the minimum appropriate number of participants required for a survey analysis is 100 therefore this volume was aimed for and 110 was attained.

Furthermore, such a sample size ensured data saturation was achieved (Tracy, 2013).

Additionally, all participants were given the opportunity to read the generic information about the study, survey and give their consent to prior to participating.

Furthermore, participants were recruited through "word of mouth" (snowball sample) (Tracy, 2013).

Lastly, all participants were either male or female, based in the UK, aged 18-65 with selfreferred levels of anxiety.

Consequently, participants who did not meet the previous criteria were excluded from the study.

\section{Instruments and Procedures}

A specifically designed online survey was developed for this study guided by the Harvard Anxiety and Depression Scale with the purpose of achieving deep exploration of experiences as the study idea in its nature was novel and specific. 
Additionally, prior to dissemination, a pilot test survey was carried out to ensure the questions were trustworthy and reliable.

Subsequently, the online survey was disseminated with elements of closed-ended, multiple-choice, scale-based and free-text questions in order to best answer the research question and capture people's feelings, emotions and thoughts.

\section{Data analysis}

The thematic analysis method (Braun \& Clarke, 2006) was used to analyze the free-text questions, uncover the most relevant themes and generate an evidence-based narrative.

A 6-phase guide to performing the analyses was performed to ensure the research question was best answered. Themes were data driven (inductive) through the following phases: "Familiarizing yourself with the data" - to submerge the researcher into the themes situated in the text; "Generating initial codes" articulating small titles to best capture what being articulated; "Searching for themes" - grouping relevant code; "Reviewing themes" - refinement developed; "Defining and naming themes" and "Producing the report".

Closed-ended questions were analyzed using the Statistical Package for Social Sciences (SPSS) software where descriptive statistics were conducted to best contextualize the findings.

\section{Results}

Quantitative analyses revealed that $62 \%$ of the study's sample size were female, $79 \%$ from a white background in conjunction with $52 \%$ being between the ages of 18-29 (Table 1). Additionally, $51 \%$ of the study's sample size experienced heightened levels of anxiety due to Covid-19 alongside $59 \%$ of individuals who reported consistent worrying thoughts (Table 1).

Furthermore, feelings of isolation were not as high among the sample although still not trivial (32\%) (Table 1).
Table 1. Illustrating important demographic characteristcs, anxiety and isolation percentages of study participants.

$$
\text { Categorical data }
$$

Percentage

\begin{tabular}{|ll|}
\hline Primary age range (18-29) & 52 \\
\hline Male & 38 \\
\hline Female & 62 \\
\hline White & 79 \\
\hline $\begin{array}{l}\text { Mixed / Multiple ethnic } \\
\text { groups }\end{array}$ & 7 \\
\hline $\begin{array}{l}\text { Asian / Asian British } \\
\text { Black / African / Caribbean / }\end{array}$ \\
$\begin{array}{l}\text { Black British } \\
\text { Other (e.g. Arab) }\end{array}$ \\
\hline $\begin{array}{l}\text { Feelings of anxiety } \\
\text { Experiencing worrying }\end{array}$ \\
$\begin{array}{l}\text { Feeling isolated } \\
\text { thoughts }\end{array}$ \\
\hline
\end{tabular}

In regards to the qualitative analyses, several connected themes and sub-themes emerged from the analyses with "family/social support" seemingly being the most significant factor for the management of anxiety and ill mental health alongside "positive feelings due to an activity" (e. g. exercise) (Table 2).

\section{Themes}

\section{High Points During the Lockdown}

In this theme, participants emphasized just how significant it was to be able to see family and friends during the lockdown and that the extra time available allowed individuals to engage in personal development. The sub-themes included the importance of Family/Social Support and Benefits of Personal Development: 
Table 2. A summary of relevant themes and sub-themes generated from the thematic analyses

\begin{tabular}{|c|c|}
\hline Themes & Sub-themes \\
\hline $\begin{array}{cr}\text { 1. High points } \\
\text { during }\end{array}$ & $\begin{array}{l}1.1 \quad \text { Importance of } \\
\text { Family/Social support }\end{array}$ \\
\hline & $\begin{array}{l}1.2 \text { Benefits of Personal } \\
\text { Development }\end{array}$ \\
\hline $\begin{array}{lr}\text { 2. Low points } \\
\text { during } & \text { the } \\
\text { lockdown } & \end{array}$ & $\begin{array}{l}2.1 \text { Lack of Family/Social } \\
\text { support \& Feelings of } \\
\text { isolation }\end{array}$ \\
\hline & 2.2 I mostly missed family \\
\hline $\begin{array}{lr}3 . & \text { Drivers } \\
\text { towards } & \text { more } \\
\text { positive feelings }\end{array}$ & $\begin{array}{l}3.1 \text { Positive feelings due } \\
\text { to an activity }\end{array}$ \\
\hline $\begin{array}{l}\text { 4. Feelings of } \\
\text { anxiety }\end{array}$ & 4. 1 Loneliness \& isolation \\
\hline $\begin{array}{l}\text { 5. Exacerbating } \\
\text { anxiety }\end{array}$ & $\begin{array}{l}5.1 \text { Uncertainty about the } \\
\text { future }\end{array}$ \\
\hline & 5.2 Fear of $2^{\text {nd }}$ wave \\
\hline $\begin{array}{l}\text { 6. Facilitating } \\
\text { Self-Care }\end{array}$ & N/A \\
\hline
\end{tabular}

\section{Importance of family/social support.}

Seeing family and friends acted as a "coping mechanism" for stress and anxiety management during lockdown with participants illustrating that "the high point of the lockdown was certainly more time for myself and my family as well as a slowly paced life in general" in addition to "high points when spending time with people virtually and physically throughout lockdown". One individual who worked in a hospital provided an insightful reflection on just how important family/social support was:

"Working for the NHS during the pandemic has been extremely stressful. We are doing more cases and people are more anxious than usual because of the risk of being infected. Due to the short staffing, we have been given more work. Night-time is even worse because we get more serious emergencies then, which makes me physically and mentally exhausted. Having said that, I am able to

\section{Selected quotation}

High points have been speaking to family and friends. (Sam)

A high point of lockdown was being able to focus more on myself. (Matthew)

Feelings of isolation and loss of personal contact with others. (Zoe)

Not being able to see friends and family from different places in the UK. (Jake)

Therapeutic! Done a small amount of gardening and cooking. (Mary)

Being cut off from family and friends and feeling alone. (Nancy)

Have felt tearful at times due to the uncertainty of things and not being able to maintain a regular routine. (Katrina)

Covid returning and being ill again as I don't feel I have the strength to face it again. (Natalie)

Talking to my family for reassurance and support. (Michelle)

get through it because I have a good support system at home, being with my family and spending time with them. This allows me to calm my anxieties. Moreover, cooking and baking acts as a good stress reliever before I go for my shifts at the hospital." (Chloe)

Furthermore, another participant articulated that having a collaborative environment at work was the key determinant in providing psychological reassurance:

"I was also able to appreciate teamwork and camaraderie at work, which I experienced working in the hospital. Knowing that somebody has my back and supports me through difficult shifts is a great reassurance during this uncertain time. I was able to focus on my physical wellbeing also, pushing myself to be healthier in the way I eat and exercise." (Georgia)

Despite the differences in context, family/social support seems to be a key psychological variable 
for providing intrinsic reassurance and inhibiting the feelings of worry and unease associated with anxiety.

\section{Benefits of personal development.}

Another high point for individuals during lockdown was the opportunity for personal development and self-reflection. Many people expressed that "time for self-improvement" and "highs have been having time to work on yourself" were of significance. Other high points for people have been to allocate their free time towards activity and movement to achieve their self-defined goals such as "losing weight, cooking meals from scratch, daily walks have been good" and "highpoints have been increased exercise activities and total control of my diet". One individual illustrated that having more time for themselves since recovering (from Covid-19) played an important role through the process of returning to full health and normality:

"Since recovering, I felt more relaxed and being able to go for walks and be in the sunshine has helped, being in furlough has helped ease the worry, recovery from illness has enabled me to get life back on track, improvement in diet and reconnecting with people has helped find normality again." (Arthur)

"I was able to improve skills for home such as gardening and cooking. Through this, I was also able to spend more time with my family and better my communication with them. This lockdown has also changed my mindset, appreciating simpler things in life, being content with what you have and finding happiness in whatever you have." (Venessa)

Thus, perhaps acting as "blessing in disguise", some individuals found that having ample free time and self-reflection sparked up dormant elements of self-development that occupied people's minds enough to engage in a journey of self-discovery and meaning; also inhibiting feelings of discomfort associated with anxiety.

\section{Low Points During the Lockdown}

In this theme, individuals expressed their feelings of isolation, loneliness and lack of family/social support as the primary factors for increasing their anxiety levels during the Covid-19 period. The sub-theme of this was isolation, especially among those who lacked family/social support, missing family and friends and anxiety.

\section{Lack of family/social support and feelings} of isolation.

In contrast to the significance of family/social support in the previous section, people who experienced a lack of such support and prolonged duration indoors underwent low mood states, feelings of depression, stress and generalized anxiety about the current environment and uncertainty about the future. Quotations such as "feelings of isolation, feeling low in general", "a low point is being isolated from friends and family", "intermittent anxiety and depression", and "feeling stressed about the uncertainty of the future" provided insightful snapshots in respect to how people felt and why. One individual managed to portray all of these concerns in their response with the lack of family support being something that "let them down":

"Worried not coping with sickness, fear of dying alone, trying to get correct medication because symptoms unclear whether COVID or just flu, lack of support while sick, isolation was difficult, depression not knowing how long this was going to last, feeling exhausted from simple tasks, having to wash, shop and cook during sickness was hard, difficult not being able to order groceries online while sick, feeling anxiety from listening to news and updates of people dying was frightening, unable to tell neighbors I was sick in case they panicked, feeling let down by family because they were too scared to help out, losing my job and worried about finances, also loss of 3 family and friends made it upsetting and real. Spent 2 months living in fear and anxiety." (Leah)

Another individual also revealed that sustained lack of contact led to feelings of anxiety and depression:

"Video calls, with friends and family. When I never got any contact for a few days, then I would start getting feelings of terrible loneliness, and would start feeling a bit depressed." (Emma)

Thus, it is evident that sustained absence of family/social support increases the chance for anxiety, feelings of depression and negative cognitive processes (self-critical \& selfdeprecating thoughts).

\section{I mostly missed family}

The last key theme was the emphasis from participants that they most missed seeing and talking to their families and friends for 
psychological reassurance and emotional support during the Covid-19 pandemic. The quotations on this theme were short but plentiful in volume:

\begin{abstract}
"Company of people, being able to hug people I care about." (Vicky)
\end{abstract}

"Being able to see my family and friends." (Jeremy)

"Human contact, I love being around people, and socializing." (Alex)

Thus, it is clear from the themes that a lack of family/social support is a determinant for the increased risk of anxiety levels and ill mental health.

\section{Drivers Towards More Positive Feelings}

Certain aspects were reported by participants to generate positivity. Sub-themes within this included participating in an activity, seeking peer support and connecting with friends and family.

\section{Positive feelings due to an activity}

In this theme, individuals who engaged in multiple activities throughout the day such as exercise, cooking, walking and virtual social meetups reported positive mood states. In general, individuals who "kept themselves busy" did not feel unworthy or unproductive thus reducing the chance for self-critical thoughts to ensue. Quotes that best portray this are as follows:

"Yesterday was a very busy day, I did tasks such as DIY around the house, shopping and exercising. I felt happy throughout the day and productive. By the end I was exhausted!" (Jessica)

"I've had an extremely fulfilled day with activities that occupied both my physical and mental needs. I've studied for an exam, went to a bar with my girlfriend and took a walk with my dog. I can easily say that l've felt relaxed and happy throughout the whole day." (Adam)

"Yesterday I woke up early \& went for a $3 \mathrm{~km}$ run followed by a 30-minute strength workout. I ate healthy but nutritious good food \& met with some of my friends who I haven't seen in a while (socially distanced). I feel really positive \& grateful that the world has slowed down \& we can really enjoy spending time with each other \& being in the moment rather than constantly rushing about." (Taylor)

"Woke up, did gardening, exercised and felt very good relaxed in evening and watched a movie and did some reading. Kept myself busy and minimized sedentary activity. Ate three meals with fruit as snacks cooked myself so felt very good doing that as felt healthy too and was extremely calm and relaxed, no stress apart from during exercise pushing my limits but I enjoy that." (Jake)

Thus although this outcome is of no surprise, it does illustrate the importance of engaging in multiple activities though out the day as a strategy for SC programs to encourage individuals to preoccupy themselves and not allow self-deprecating thoughts and worries to "creep in".

\section{Feelings of Anxiety}

In contrast to those who felt positive, numerous people during lockdown felt "sluggish" and unmotivated to partake in regular daily activities due to feelings of isolation, loneliness, uncertainty about the future and fear of a second Covid-19 wave all fueling a generalized feeling of unease and fear. Some people felt "near breakdown" whilst others described their feelings as "felt slightly down but hopefully things will get better soon".

\section{Loneliness and isolation}

Loneliness and isolation were feelings that people experienced during the lockdown period that contributed towards the generalized feeling of worry, unease and thus anxiety. Quotations such as "feeling lonely sometimes" and "being alone, feeling restricted" provided insight that people felt helpless and trapped. Further quotations were:

"Excess free time, isolated from family." (Ben)

"Day passed o.k. But then I would get feelings of loneliness, I get this more than I did, before lockdown." (Alex)

"During the day I am able to cope, in evenings, feelings of depression, unable to talk to someone because people feel overburdened hearing about my health. Daytime been out walking and to get fresh air for change of environment, seeing people with friends and loved ones, feel isolation even more, having to socially distance. People don't want me 
to visit because I have been ill and they are worried of me being asymptomatic and a carrier." (Sonia)

\section{Exacerbating Anxiety}

Another key theme was that it was clear that participants were faces with troubled thoughts during the pandemic that exacerbated their anxiety. Subt-themes within this included Uncertainty about the future and Fear of 2 nd wave.

\section{Uncertainty about the future}

In conjunction with the previous sub-theme, individuals reported a sense of "future uncertainty" and "fear of the unknown" as mechanisms driving ill thought and worry. Quotations such as "the uncertainty of all our futures scares me "and what will the future look like, fear of the unknown" illustrate the gravity of how fearful people were about future events. Due to the environment being so volatile and negative, this could potentially explain why individuals felt so insecure about the future in conjunction with personal specific circumstances that further amplified this feeling increasing the risk of anxiety and health-debilitating behaviors.

\section{Fear of $2^{\text {nd }}$ wave}

Due to the infectious nature of the virus and chaotic environment that transpired after, many people felt frightened of the possibility for a second wave unfolding with more Covid-19 deaths. Quotations such as "dreading a second wave of Covid-19" and "I fear the virus may return and kill more people" briefly illustrates the severity of fear and negative cognitive processes that were occurring in people's minds. Further quotations include:

"Fears that there may be a second wave and $i$ or people I know may get ill and/or die." (Marva)

"Fears - a second wave of the virus." (Pam)

"That people have and are still not taking the Pandemic seriously and that a second one may occur. I worry that I could go out and bring Covid 19 back to my husband." (Finola)

"Fear of a second wave of infections." (Daniel)

Thus, this sub-theme may have acted as an adjunct contributing towards the proclivity for generalized anxiety to be experienced. Despite this, it is clear that the reasons for increased anxiety during lockdown are multifactorial and situation specific in respect to how it is developed for each person. More importantly, irrespective of individual intention and activity, environmental influence plays a significant role in changing behavior and consequently, SC programs that reduce environmental variance should be facilitated.

\section{Facilitating Self-Care}

Family/social support acted as a "coping mechanism" for the management of anxiety levels however, this theme illustrates that ongoing family/social support was not only a "coping mechanism" but also acted as a determinant for positive mental health outcomes and inhibition of anxiety and ill-related thoughts. Quotations such as "support from family and friends" and "being able to have virtual contact with friends through face time" are just a couple of insights vocalized by participants. One person explained how ongoing support provided intrinsic reassurance and due to such a phenomenon allowed her to stay calm through such an uncertain time:

"Family and friends has been a great support network for me to move through this lockdown. Through the help of social media, I am able to communicate with friends and family even from my native home in Philippines. It reassured me that I am not alone during this time." (Sarah)

Others provided less depth and insight but emphasized the same principle from different perspectives:

"Feeling supported but my family that allowed be to stay calm about life and accept that what was going on was out of my control." (Debbie)

"Focusing on my faith and reuniting virtually with family and friends." (Ally)

"Talking to family and friends about how I am feeling." (Natalie)

"Support from friends and family." (Ryan)

"Seeing a therapist, going for walks and speaking to friends and family most days and avoiding the news." (Louise)

"Lots of family contact with phone and video calls." (George)

Despite the lack of depth, there was an overwhelming emphasis on just how significant ongoing family/social support played for individuals during the Covid-19 pandemic towards their mental wellbeing. It is clear that a 
SC program facilitating a therapeutic environment through dialogue where individuals can vicariously share emotion and experience is paramount

\section{Discussion}

From the results presented, areas of interested can be identified. Firstly, it is apparent that both a lack of and a sustained reciprocation of ongoing family/social support is a key predictor for the proclivity of anxiety-inducing thoughts to be experienced; secondly, in this study the "byproducts" of reduced family/social support led to negative thought processes and feelings such as isolation, loneliness and uncertainty about the future; and lastly, individuals who continually engaged in activity experienced positive mood states irrespective of the current lockdown environment.

As Covid-19 is a global pandemic and crisis, the findings from this study, particularly around the importance of peer support as a mediator for positive mental health outcomes, is supported by literature that has captured the psychological impact of global crisis events on individual, community and international levels such as the ill mental health experienced in warzones (Summerfield, 2000), coping mechanisms derived from individuals who had experienced the Ebola virus outbreak in Africa in 2014 (Bortel et al., 2016) and the previous Coronavirus disease (SARS) that occurred in China in 2003 (Tolomiczenko, 2005). Summerfield, (2000) emphasises that "personal recovery is grounded in social recovery" and that "rights and social justice shape collective healing". Although the environment of warzones may compound the feelings of anxiety more due to its violent nature, ill-related thoughts and feelings of bereavement, guilt, mistrust of public services, generalised anxiety and fear about the uncertainty of future events (Summerfield, 2000) are all relatable findings to this dissertation. Additionally, even in this traumatic context, peer support groups, where people share insight, experiences, thoughts and emotion, seem to facilitate an environment of trust and rapport that helps nurture and develop health-promotion strategies (Coatswroth, Forchuk, \& Griffin, 2006; Summerfield, 2000). In contrast to this, individuals in warzones who lacked community acknowledgement and support felt rejected, abandoned and isolated that increased the inclination of antisocial behaviours and depressive thoughts (Puspoky et al., 2006; Summerfield, 2000) which can also be seen in the context of Covid-19 as individuals who received a lack of peer support and sense of belonging emphasised similar feelings. Comparable findings can also be found during the Ebola virus outbreak where survivors at an individual level, who felt rejected, stigmatised and abandoned by their community experienced feelings of anxiety, depression, isolation, self-harm, worthlessness, sadness and self-stigmatisation (Bortel et al., 2016; James, Wardle, Steel, \& Adams, 2019). In conjunction with this, and similar to the environment of Covid19, the economy of West Africa plummeted due to the Ebola virus outbreak which further influenced the social fabric and rapport between communities and consequently creating a "breeding ground" for anxiety and self-destructive behaviours to ensue (Huber, Finelli, \& Stevens, 2018). However, despite the severity and death toll of the Ebola virus outbreak, behavioural coping strategies to tackle and recover from past traumatic experiences involved socialisation/peer support and a commitment to faith as a collective identity to foster a sense of belonging (Bortel et al., 2016; James et al., 2019) which again, is somewhat replicable to the coping strategies of people during the Covid-19 pandemic. Acting as an adjunct to the previous findings, data collected from the previous SARS outbreak, in an hospital environment, confirmed that nurses who lacked the peer support from their physicians/doctors, felt burned out, less informed about the development of SARS, less involved in decision making, rejected and consequently, experienced feelings of worry that affected moral, job satisfaction and fulfilment (Tolomiczenko, 2005). This finding is useful as the environment of the previous SARS outbreak in the hospital domain is likely to be replicable to the current hospital environment of Covid-19 and also confirms the need for peer support to ensure staff are nurtured for and that patient centred care isn't compromised. Thus, despite the differences in environment, there is a universal theme that ongoing peer support as a SC behaviour for anxiety management is beneficial in the context of social upheaval however, a tailored SC strategy for anxiety self-management in the context of Covid-19 is still warranted.

Wu, Connors and Everly, (2020) looked at the previous response to SARS in the context of hospitals and emphasised the need for leadership, cohesion and ongoing support for staff to ensure they felt resilient enough to bare the overwhelming responsibility of Covid-19; whilst new research looking into the mental health consequences of Covid19 advocate the need for "population-level interventions targeted at the prevention and treatment of mental health symptoms (e.g. anxiety) and at boosting coping and resilience (e.g. exercise)" (Holmes et al., 
2020). Perhaps the most promising strategy for successful adherence towards an anxiety selfmanagement intervention post pandemic is online SC (self-help) programmes (Sahni, Singh, Sharma, \& Garg, 2021), in particular "self-help guidance on demand" (Brog, Hegy, Berger, \& Znoj, 2021). Firstly, integrating self-help programmes for anxiety online concur with current social distancing measures, do not require physical contant, facilitate peer support and are scalable (Brog et al., 2021; Rosen, Glassman, \& Morland, 2020). Secondly, a "guidance on demand" approach imples that patients can request therapist assistance when needed whilst still being able to experience unguided (automated) self-help thus promoting cost effectivness (Brog et al., 2021) and preserving autonomy, an important mechanism for establinsing rapport (Bandura, 2004). Most importantly, randomised controlled trials assessing the effectivness of "guidance on demand" on anxiety have been conducted with "guidance on demand" showing similar positive reductions to that of usual care (in person) or "guided self-help" (online with therapist). For instance, Krieger et al. (2019) carried out a 8week, compassion focused intervention with usual care combined with "guidance on demand" and usual care alone on individuals who experienced overly self-critical cognitions and found significant medium-large effect sized reductions in self-deprecating thoughts in favour of the intervention group. Similarly, Kleiboer et al. (2015) conducted a 6-week online intervention based on problem solving therapy with the "guidance on demand" group showing identical reductions in anxiety symptoms as the unguided mode of the programme. Likewise, both Krieger et al. (2019) and Kleiboer et al. (2015) findings can be strengthened by additional evidence (Berger et al., 2011; Rheker, Andersson, \& Weise, 2015). Thus, it would be safe to assume that best mode of SC for anxiety moving forwards could be online "guidance on demand".

In the final analysis, amalgamating online, "guidance on demand", with an activity such as walks (virtual walking groups) or cooking due to its popularity might be an appropriate strategy. Specifically, the "guidance on demand" aspect can promote peer support that acts as a "environmental mechanism" for rapport building through the phenomenon of socialisation and empathy (Smith, 2006) in conjunction with the positive behavioural feedback loop, explained through the SCT (Bandura, 2004), fostering an hedonistic experience and increasing the inclination for adherence towards this pattern of behaviour. Additionally, and to the best of the authors knowledge, no studies have been carried out this way that would be of use to the area of anxiety self-management. Furthermore, in addition to the benefits from peer support, simply moving would already provide additive benefits both physically and psychologically (ACSM, 2016, 2017) as sedentary behaviour would be reduced. In summary, a SC programme that encompasses peer support with an activity such as walking, cooking or even aerobic exercise should be a cost-effective suitable strategy for helping individuals self-manage their anxiety more competently and reducing the proclivity to submit to negative cognitive processes and engagement in self-destructive behaviours.

\section{Impact of Findings}

The findings of this study are influential, insightful and pragmatic in guiding future health care professionals, from both primary and secondary care services, in producing a program or self-help materials for anxiety. Consequently, in doing so should act as the first step towards reduced NHS pressure and costs. Secondary community health services (e.g. talking groups, weight management, exercise referral) in particular benefit from this study as it would be useful to facilitated SC programs fueled with social support and activity in an attempt to manifest socialization, rapport building, hedonism and thus adherence towards this mode of behavior.

\section{Limitations of the study $\backslash$ Strengths of the study:}

This study adds to novel literature and is one of the first of its kind to obtain insight into people's perceptions, feelings, worries and thoughts about the current uncertain environment of Covid-19 and how people self-manage their anxiety however, this study isn't without its limitations. By its nature, surveys only provide limited insight as it is difficult to portray true feelings and emotions via this mode of data collection. Additionally, some questions were left unanswered in conjunction with individuals potentially providing dishonest answers or just answering the questions with what "the researcher wanted to hear". Furthermore, some questions may have been comprehended and interpreted differently between each participant despite the researcher's best efforts. It is also important to acknowledge that the findings of this study are only applicable to adults and thus cannot apply to any population outside this age range. Still, despite this both quantitative and qualitative methods were used to facilitate a holistic approach and absorb as much of the 
relevant findings where possible to generate a useful valid evidence-base narrative. Additionally, as more than 100 individuals completed the survey some trustworthiness, reliability and saturation can be established. In respect to future research suggestions, it would be useful to focus on the quantitative analyses for this research topic and compare different age groups towards anxiety levels in terms of severity; as this research focused on the qualitative aspect, this analyses was deemed outside the remit for this particular study. Furthermore, as peer support presented itself as being the most influential element of anxiety management, future SC interventions amalgamating peer support with an activity such as walking (walking groups) or cooking (virtual or in person) and using the HADS scale pre, during and post intervention alongside qualitative interviews may be one of many appropriate research strategies acting as a "stepping stone" towards a future SC program promoting anxiety selfmanagement.

\section{Conclusion}

In conclusion, the findings from this study adds to current novel literature on the current anxiety levels of adults living in the UK under the Covid-19 pandemic and what behaviors people adopt to self-manage their anxiety levels. Furthermore, this study highlights the significance of ongoing peer support as a SC behavior that can act as a positive meditator for healthy cognitive processes to ensure that inherently reduces the risk of anxiety levels and ill mental health. Thus, future health care initiatives that seek to facilitate SC and promoting this strategy may, if not prevent, at least slow down the rising cases of anxiety and ill mental health due to the uncertain environment Covid-19 plus other future pandemics might produce.

\section{Conflict of interest}

The authors declare no conflict of interests

\section{References}

Appleby, L., Shaw, J., \& Amos, T. (1997). National confidential inquiry into suicide and homicide by people with mental illness. The British Journal of Psychiatry, 170(2), 101-102.

American College of Sports Medicine. (2016). Exercise management for persons with chronic diseases and disabilities. Champaign, IL: Human Kinetics.

American College of Sports Medicine. (2017). Guidelines for exercise testing and prescription. Philadelphia, PA: Wolters Kluwer.
Aherne, D., Farrant, K., Hickey, L., Hickey, E., McGrath, L., \& McGrath, D. (2016). Mindfulness based stress reduction for medical students: optimising student satisfaction and engagement. BMC medical education, 16(1), 209.

Appleby, L., Shaw, J., \& Amos, T. (1997). National confidential inquiry into suicide and homicide by people with mental illness. The British Journal of Psychiatry, 170(2), 101-102.

Byrom, N. (2018). An evaluation of a peer support intervention for student mental health. Journal of Mental Health, 27(3), 240-246.

Bortel, T., Basnayake, A., Wurie, F., Jambai, M., Koroma, A. S., Muana, A. T., ... \& Nellums, L. B. (2016). Psychosocial effects of an Ebola outbreak at individual, community and international levels. Bulletin of the World Health Organization, 94(3), 210.

Bocking, J., Ewart, S. B., Happell, B., PlataniaPhung, C., Stanton, R., \& Scholz, B. (2018). "Here if you need me": exploring peer support to enhance access to physical health care. Journal of Mental Health, 27(4), 329335.

Baker, C. (2020). Mental health statistics for England: prevalence, services and funding. House of Commons Library, 6988.

Bandura, A. (2004). Health promotion by social cognitive means. Health education \& behavior, 31(2), 143-164.

Bandura, A. (1997). Self-efficacy: The exercise of control. New York, NY: Freeman.

Braun, V., \& Clarke, V. (2006). Using thematic analysis in psychology. Qualitative Research in Psychology, 3(2), 77-101.

Bhuyan, K. K. (2004). Health promotion through self-care and community participation: elements of a proposed programme in the developing countries. BMC public health, 4(1), 11.

Brog, N. A., Hegy, J. K., Berger, T., \& Znoj, H. (2021). An internet-based self-help intervention for people with psychological distress due to COVID-19: study protocol for a randomized controlled trial. Trials, 22(1), 1-11.

Berger, T., Caspar, F., Richardson, R., Kneubühler, B., Sutter, D., \& Andersson, G. (2011). Internetbased treatment of social phobia: a randomized controlled trial comparing unguided with two types of guided selfhelp. Behaviour research and therapy, 49(3), 158-169.

Connor, R. C., \& Kirtley, O. J. (2018). The integrated motivational-volitional model of suicidal behaviour. Philosophical Transactions of the Royal Society B: Biological Sciences, 373(1754), 2017-2068. 
Coatsworth-Puspoky, R., Forchuk, C., \& WardGriffin, C. (2006). Peer support relationships: an unexplored interpersonal process in mental health. Journal of psychiatric and mental health nursing, 13(5), 490-497.

Dean, K., \& Kickbusch, I. (1995). Health related behaviour in health promotion: utilizing the concept of self-care. Health Promotion International, 10(1), 35-40.

Decker, J. T., Brown, J. L. C., Ashley, W., \& Lipscomb, A. E. (2019). Mindfulness, meditation, and breathing exercises: reduced anxiety for clients and self-care for social work interns. Social Work with Groups, 42(4), 308322.

Department of Work \& Pensions. (2019). Households below average income: 1994/95 to 2018/19. Retrieved from https://www.gov.uk/government/statistics/hous eholds-below-average-income-199495-to201819

Elovainio, M., Hakulinen, C., Pulkki-Råback, L., Virtanen, M., Josefsson, K., Jokela, M., ... \& Kivimäki, M. (2017). Contribution of risk factors to excess mortality in isolated and lonely individuals: an analysis of data from the UK Biobank cohort study. The Lancet Public Health, 2(6), e260-e266.

Frasquilho, D., Matos, M. G., Salonna, F., Guerreiro, D., Storti, C. C., Gaspar, T., \& Caldas-de-Almeida, J. M. (2015). Mental health outcomes in times of economic recession: a systematic literature review. $B M C$ public health, 16(1), 115.

Freedman, L. (2020). Strategy for a Pandemic: The UK and COVID-19. Survival, 62(3), 25-76.

Foley, N. (2020). Unemployment by ethnic background. House of Commons Library: Briefing Paper Number, 1, 6385.

Farmer, N., Touchton-Leonard, K., \& Ross, A. (2018). Psychosocial benefits of cooking interventions: a systematic review. Health Education \& Behavior, 45(2), 167-180.

Gillard, S. (2019). Peer support in mental health services: where is the research taking us, and do we want to go there?. Journal of Mental Health, 28, 341-344.

Holmes, E. A., O'Connor, R. C., Perry, V. H., Tracey, I., Wessely, S., Arseneault, L., ... \& Ford, T. (2020). Multidisciplinary research priorities for the COVID-19 pandemic: a call for action for mental health science. The Lancet Psychiatry, $7(6), 547-560$.

Huber, C., Finelli, L., \& Stevens, W. (2018). The economic and social burden of the 2014 Ebola outbreak in West Africa. The Journal of Infectious Diseases, 218(5), 698-704.

James, P. B., Wardle, J., Steel, A., \& Adams, J. (2019). Post-Ebola psychosocial experiences and coping mechanisms among Ebola survivors: a systematic review. Tropical Medicine \& International Health, 24(6), 671691.

Krieger, T., Reber, F., von Glutz, B., Urech, A., Moser, C. T., Schulz, A., \& Berger, T. (2019). An internet-based compassion-focused intervention for increased self-criticism: a randomized controlled trial. Behavior therapy, 50(2), 430-445.

Kleiboer, A., Donker, T., Seekles, W., van Straten, A., Riper, H., \& Cuijpers, P. (2015). A randomized controlled trial on the role of support in Internet-based problem solving therapy for depression and anxiety. Behaviour research and therapy, 72, 63-71.

Kef, K. (2021). COVID-19: The Level of Knowledge, Anxiety and Symptom Presentation. Psychology Research and Behavior Management, 14, 541.

Kotrlik, J. W. K. J. W., \& Higgins, C. C. H. C. C. (2001). Organizational research: Determining appropriate sample size in survey research appropriate sample size in survey research. Information technology, learning, and performance journal, 19(1), 43.

Lawn, S., Smith, A., \& Hunter, K. (2008). Mental health peer support for hospital avoidance and early discharge: an Australian example of consumer driven and operated service. Journal of Mental Health, 17(5), 498508.

Mahase, E. (2020). Covid-19: Mental health consequences of pandemic need urgent research, paper advises.

Matthews, T., Danese, A., Caspi, A., Fisher, H. L., Goldman-Mellor, S., Kepa, A., ... \& Arseneault, L. (2019). Lonely young adults in modern Britain: findings from an epidemiological cohort study. Psychological medicine, 49(2), 268-277.

Mikkelsen, K., Stojanovska, L., Polenakovic, M., Bosevski, M., \& Apostolopoulos, V. (2017). Exercise and mental health. Maturitas, 106, 48-56.

National Health Service. (2018a). Generalized anxiety disorder in adults. Retrieved from https://www.nhs.uk/conditions/generalisedanxiety-disorder/

National Health Service. (2018b). Yoga. Retrieved from

https://www.nhs.uk/livewell/exercise/guide-toyoga/

O'Connell, M. J., Flanagan, E. H., DelphinRittmon, M. E., \& Davidson, L. (2017). Enhancing outcomes for persons with cooccurring disorders through skills training and peer recovery support. Journal of Mental Health, 29(1), 6-11. 
Puschner, B. (2018). Peer support and global mental health. Epidemiology and psychiatric sciences, 27(5), 413-414.

Public Health England. (2018). Health matters: reducing health inequalities in mental illness. Retrieved from https://www.gov.uk/government/publications/h ealth-matters-reducing-health-inequalities-inmental-illness/health-matters-reducing-healthinequalities-in-mental-illness

Ryan, R., \& Deci, E.L. (2000). Self-determination theory and the facilitation of intrinsic motivation, social development and wellbeing. American Psychologist, 55 (1), 68-78.

Rosen, C. S., Glassman, L. H., \& Morland, L. A. (2020). Telepsychotherapy during a pandemic: A traumatic stress perspective. Journal of Psychotherapy Integration, 30(2), 174.

Rheker, J., Andersson, G., \& Weise, C. (2015). The role of "on demand" therapist guidance vs. no support in the treatment of tinnitus via the internet: a randomized controlled trial. Internet Interventions, 2(2), 189-199.

Stussman, B. J., Black, L. I., Barnes, P. M., Clarke, T. C., \& Nahin, R. L. (2015). Wellness-related use of common complementary health approaches among adults: United States, 2012. National Health Statistics Reports, (85), $1-12$.

Smith, A. (2006). Cognitive empathy and emotional empathy in human behavior and evolution. The Psychological Record, 56(1), 321.

Summerfield, D. (2000). War and mental health: a brief overview. BMJ, 321(7255), 232-235.

Sahni, P. S., Singh, K., Sharma, N., \& Garg, R. (2021). Yoga an effective strategy for selfmanagement of stress-related problems and wellbeing during COVID19 lockdown: a crosssectional study. PloS one, 16(2), e0245214.

Sahu, K. K., \& Kumar, R. (2020). Preventive and treatment strategies of COVID-19: From community to clinical trials. Journal of family medicine and primary care, 9(5), 2149.

Tolomiczenko, G. S., Kahan, M., Ricci, M., Strathern, L., Jeney, C., Patterson, K., \& Wilson, L. (2005). SARS: coping with the impact at a community hospital. Journal of advanced nursing, 50(1), 101-110.

Tracy, S. J. (2013). Qualitative research methods: collecting evidence, crafting analysis, communicating impact. Oxford, UK: WileyBlackwell.

Utter, J., Denny, S., Lucassen, M., \& Dyson, B. (2016). Adolescent cooking abilities and behaviors: Associations with nutrition and emotional well-being. Journal of nutrition education and behavior, 48(1), 35-41.
Weir, B., Cunningham, M., Abraham, L., \& Allanson-Oddy, C. (2019). Military veteran engagement with mental health and wellbeing services: A qualitative study of the role of the peer support worker. Journal of Mental Health, 28(6), 647-653.

Wu, A. W., Connors, C., \& Everly Jr, G. S. (2020). COVID-19: peer support and crisis communication strategies to promote institutional resilience. ACP Journals, 1, 1-2.

World Health Organisation. (2019). What do we mean by self-care. Retrieved from https://www.who.int/reproductivehealth/selfcare-interventions/definitions/en/ 